\title{
Replacing the Lab Manual with a Learning Management System in Physics Investigations for K-4 Pre-service Teachers
}

\author{
Stanley Sobolewski*, Muhammad Z. Numan \\ Department of Physics, Indiana University of Pennsylvania, Indiana, Pennsylvania 15705, USA
}

Copyright $\bigcirc 2018$ by authors, all rights reserved. Authors agree that this article remains permanently open access under the terms of the Creative Commons Attribution License 4.0 International License

\begin{abstract}
The traditional laboratory investigation uses a procedure written on paper; students then record their responses on a supplied data page or laboratory notebook. In an attempt to make this process more efficient, the use of a Learning Management System (in this case D2L) was used to present the material and collect student feedback. Each student had a University supplied laptop, read the procedure from the screen and submitted answers through D2L. As anticipated there was no change in content knowledge. However surprisingly, subjects felt the paper and pencil approach was easier to use than computer entry. In a subsequent study, the same population in the same course completed an on-line only lecture and lab course. We will discuss the student's reaction to this on-line class.
\end{abstract}

Keywords Physics Labs, Pre-service Teachers, On-line Learning

\section{Introduction}

Digital interface devices such as smartphones, tablets, and laptops have become ubiquitous; most college students have a smart phone. If this fact is combined with the increased interest in on-line learning on the part of both colleges as well as students, it is apparent the future of instruction will involve more of these devices. In the past, the cost of acquiring these devices has been the burden of the institution; the drop in cost and size of the devices indicates that a majority of college students will bring their own device to class. Eventually having a personal media device might be a class requirement similar to paper, pencil and a notebook. The advantages of using this technology in the traditional class room could include immediate feedback for students, ease in editing text and material provided by the instructor and quick comparison and sharing of data and information amongst the students.

The intent of this study was to determine if a traditional laboratory activity would be perceived more favorably than a paper and pencil activity. The ultimate goal of this project is not to develop online laboratories but to use a learning management system to facilitate student feedback during a traditional laboratory activity. The objective is not to enhance learning, but to determine the efficiency of this mode of student instruction.

\section{Theoretical Background}

Technology is ubiquitous. At a very elementary level an LMS enhances instruction by allowing instructors to submit PowerPoint slides for later student review. (Gnitetskaya, Ivanova, \& Cherednychenko [1] ) There are many platforms and types of LMS and while in this situation the LMS is selected by the institution, it should be mentioned that when comparing Learning Management Systems, most of the considerations seem to deal with technical issues on the hardware and software issues, and there is little if any discussion on pedagogical issues between the LMS.(Caminero et al., [2] )

Moodle is a free and open sourced LMS that has success in enhancing physics instruction. (Martín-Blas \& Serrano-Fernández, [3] ) Martin-Blas has found that e-learning techniques offered through Moodle have evaluated the improvement of the academic results of first year physics students. It was found that students who used Moodle regularly during the semester obtained higher scores in the course than the students who did not.

A straight forward method to use computers in instruction is to have students solve problems and receive feedback; toward this end, Crippen developed an example database for General Chemistry. (Crippen \& Earl [4] ) Participants in their study had access to web content quizzes for 1 week. During this period, students could modify their responses at any time as their skills and understanding of the material change. The quizzes are graded, with correct/incorrect results and the correct 
answers provided, at the end of the week. Principally, these assessments are designed as a learning opportunity. Participants were encouraged to review worked examples along with self-explanation of the problem. The combination of a worked example with a self-explanation prompt produces improvement in performance, problem-solving skill, and self-efficacy.

Lee examined the use of various levels structured support or preparation provided students before problem-solving. It was found that interactive tutorials are beneficial when the support provided is "just in time" so as to reduce the cognitive load during the problem-solving. In the context of what is being done here, students need just minimal amount of guidance during the laboratory activities. (Lee [5] )

A dedicated physics website, entitle Getsmart was developed to enhance students' knowledge of concepts in physics. The site included web-based lessons, tests, chat rooms and other web media. (Chandra \& Watters, [6] )

Psycharis (Psycharis, Chalatzoglidis, \& Kalogiannakis [7] ) found that Learning Management Systems are not always popular with the students, for a number of reasons. Students report that they experience difficulties in technical issues, lack of familiarity with the system and discussion overload. However, in general, students express positive attitudes towards their intention to use Moodle for teaching and learning Natural Sciences.

A teaching strategy which can be parallel to, but not necessarily limited to Learning Management Systems is the use of computer simulations. The University of Colorado, Boulder is a repository for the PhET simulations, research-based computer simulations for teaching and learning physics. They are freely available from the PhET website. The simulations are animated, interactive, and game-like environments where students learn through exploration. These simulations have been used in many levels of physics instruction. Even learning in topics as challenging as Quantum Mechanics can be enhanced with computer simulations. (McKagan et al. [8] ) It was found that simulations to be effective in helping students learn, and reveal new insights into how students think about quantum mechanics.

This activity was not on-line by the strict definition since the instructor was always present in the room with the students. However, in some elements of this instruction do share on line characteristics. Elements of an effective on-line science course include (Jeschofnig \& Jeschofnig [9] )

- A course schedule that identifies all required assignments and experiments by due date.

- A lab report rubric that clearly explains the course diagnostic for the students

- Equation editor tools that are intuitive for students to use
- Chat -collaboration tools that allow students to exchange explanations and understanding between themselves and their instructor

- A good lab kit with experiments that communicate the analytical to empirical meaning of the subject matter and allow students to see firsthand how the physical world response to stimuli.

- A lab manual that clearly explains all procedural steps and sets the stage for the experiment and empirical results expected.

- Instructors should be proactive in pointing out potential problems areas where students often encounter difficulties. For example, physics students working with electric circuits often set their digital millimeters incorrectly and blow the fuse. They are less likely to do this if their instructor gives them prior warning via the lab discussion board.

Essentially, all of the above steps were followed during the development of the experimental lesson.

\section{Methodology}

Initially, the intent was to use $\mathrm{D} 2 \mathrm{~L}$ as a platform to display laboratory procedure as well collecting student responses. Students would read a procedure from the web page, perform the activity as described and enter data in D2L. The anticipation was that feedback would be given immediately. D2L has been used at the University for several years, and the author has taught several courses both on-line and in person using this LMS. One of the goals of this study is to compare the student acceptance of types of input. The control method of input is using pencil on paper; this method has been used extensively in the past. An upcoming technology is using a stylus on a screen to digitize had writing. While this is an exciting possibility, that technology was not available. The laptop computers were provided by the university and were not equipped with this input method. It has also been shown that acceptance rates of survey respondents to tables versus paper and pencil were no different.

An unexpected problem was in most all quizzing modules the initial data or information was supplied by the instructor. As an example, if the instructor wanted to have a question on density, the instructor provides the mass and volume, and the student would have to manipulate the values to find density. In the proposed environment, the student would measure the mass and volume, and then use that data to calculate a density. The LMS would then compare its calculation to the students calculation and determine how close the student's calculation is to its own. It was found that D2L cannot receive input from the user and use that data to calculate a value which is then compared to a student calculation. 


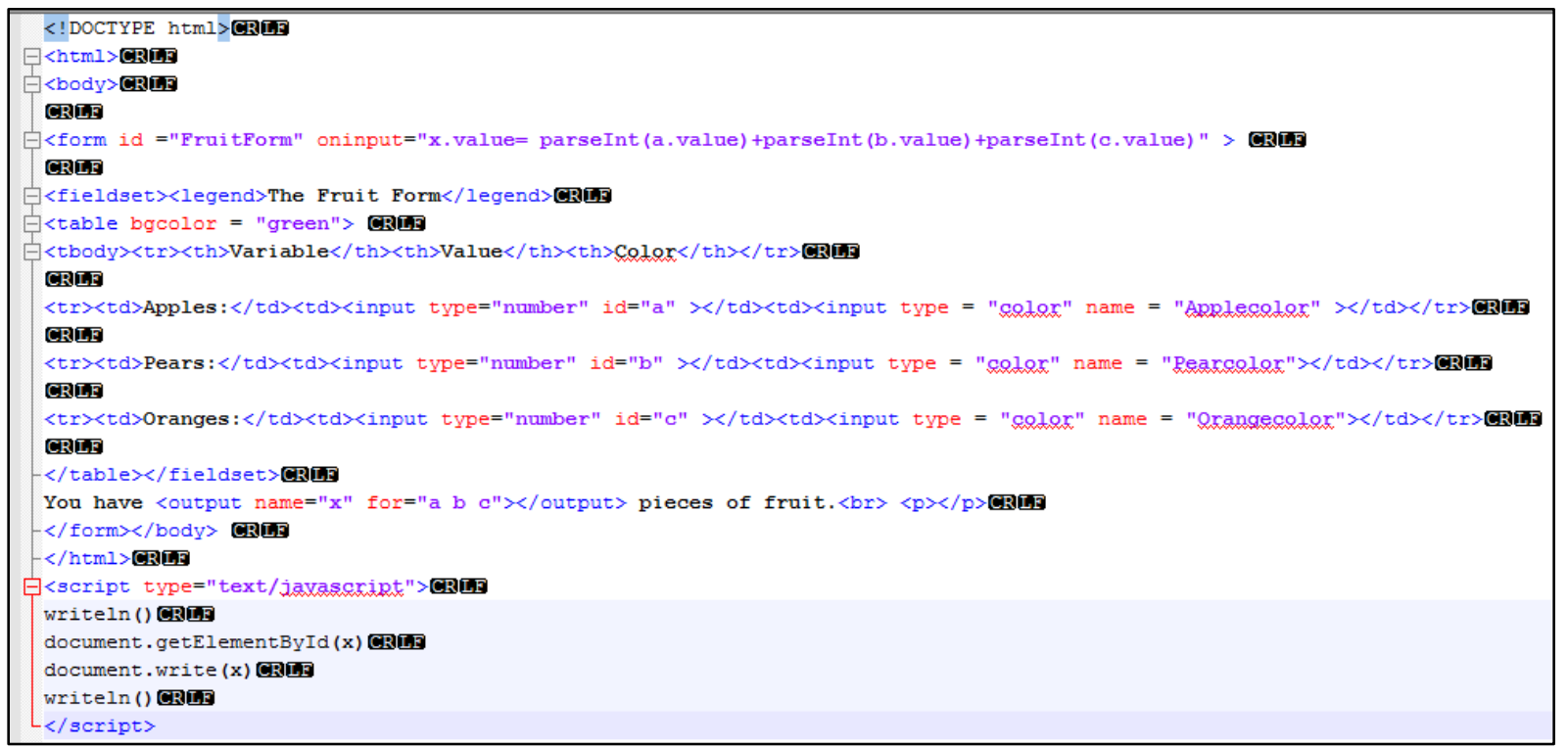

Figure 1. HTML script

The HTML script (Figure 1) produces the following results (Figure 2)

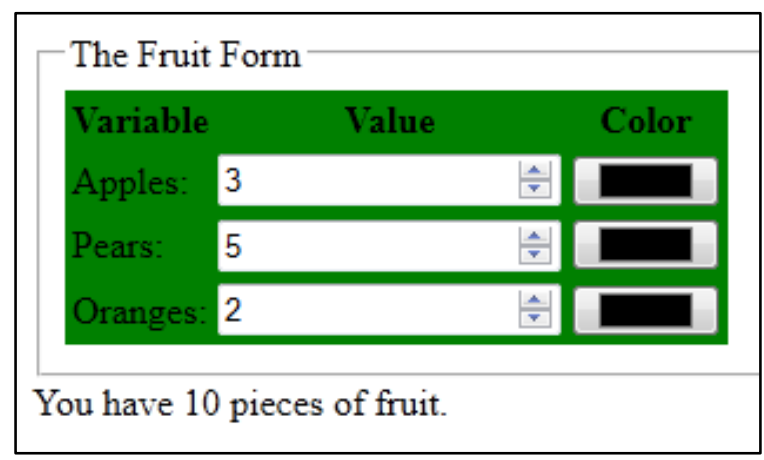

Figure 2. HTML script output

While it was straight forward to have D2L display the results of simple calculations, there was no straight forward way to save this data into a D2L file for comparison with future data or calculations. After spending three to four weeks exploring HTML techniques, as well as embedding Java in the web pages, time was running short and the idea of producing custom tables was abandoned. However, students could still enter values into the quiz module; they would need to be manually graded. Another issue, perhaps less critical, is the formatting of LMS pages. In the traditional paper and pencil lab report, data is organized in tables.

\begin{tabular}{|c|c|c|c|}
\hline \multicolumn{5}{|c|}{ Mass and Speed Data } \\
\hline $\begin{array}{c}\text { Mass } \\
(\mathrm{g})\end{array}$ & $\begin{array}{c}\text { Distance from } \\
\text { A to B }(\mathrm{cm})\end{array}$ & $\begin{array}{c}\text { Time from } \\
\text { A to B }(\mathrm{sec})\end{array}$ & $\begin{array}{c}\text { Speed } \\
(\mathrm{cm} / \mathrm{sec})\end{array}$ \\
\hline & & & \\
\hline & & & \\
\hline & & & \\
\hline & & & \\
\hline
\end{tabular}

Figure 3. Typical Paper and Pencil Data Table

The table on the top (Figure 3) is one the paper and pencil lab report. Below that is the D2L quiz (Figure 4) that gathered the same data. The Speed from $A$ to $B$ calculation was entered on a different quiz question. This was an adequate table; however as stated above, the instructor would manually grade the answers. 


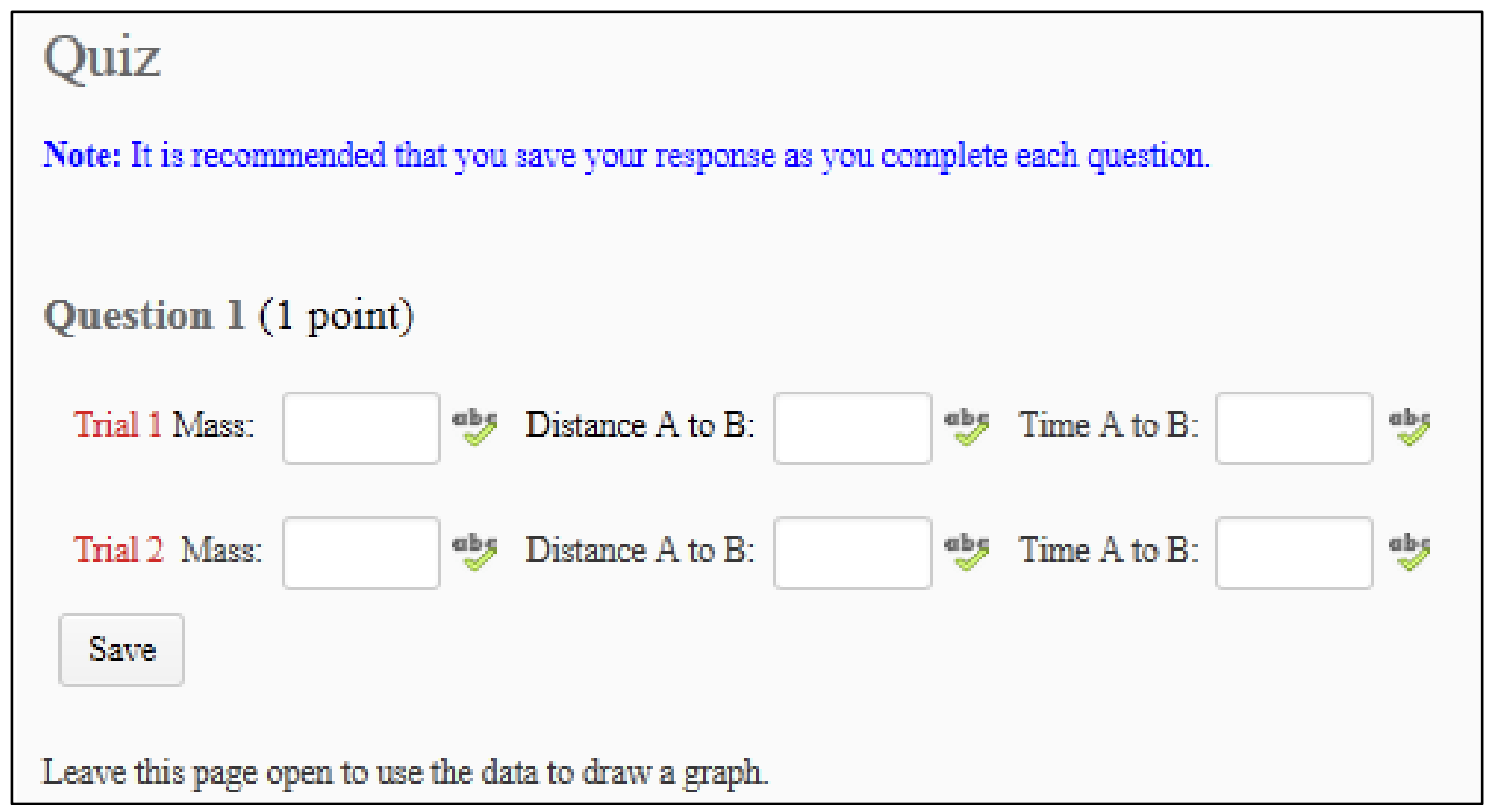

Figure 4. D2L Data Table

Population - the subjects for this study were students pursuing certification to teach Pre-K to $4^{\text {th }}$ grade; in addition they will also become certified in special education. The special education certification is part of the program to enhance marketability to students in the program. They are enrolled in a 4-year degree program; graduates receive a Bachelor of Science in Education. There is no math or physics course pre-requisites for this class; two of the students in the class did take physics in high school. Subject's responses were compared to the general population enrolled in this lab course. While no specific section was identified as a "control group", there are scores of course sections offered every semester. The response of the experimental group is compared to a random selection from other sections throughout the semester.

Procedure - The subjects were enrolled in a linked laboratory-lecture course, loosely modeled after the CPO Curriculum "Conceptual Physical Science" developed by Tom Hsu. [10] During normal laboratory course operation, students would read a procedure from a published laboratory manual, as they followed the procedure. Students would provide answers on a provided answer page. Occasionally they would need to sketch a graph or draw a picture. The curriculum is based on the inquiry model; where students are presented with a situation and then asked to make a prediction about the situation. After this prediction, students take a measurement to refute or verify the prediction. An example would be a light bulb in a DC circuit. Students measure the current entering the bulb and then are asked to predict the current leaving the bulb. Once the prediction has been recorded; the student measures the current leaving the light bulb. More than once, the students are astounded their predictions are incorrect.

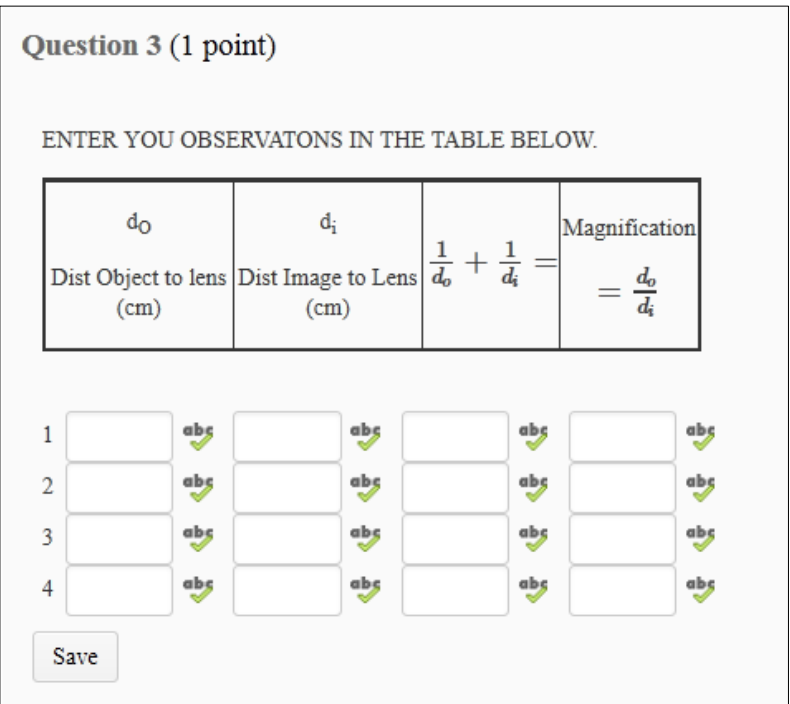

Figure 5. Data Table in D2L Quiz Format

For this specific study, one investigation normally presented on a printed page where the students used pencils to respond was replaced with text and questions presented through a learning management system (LMS). D2L was used since that is the LMS adopted by the university. The objectives, instructions and text from the printed lab manual were ported into D2L as informational text. Students would answer questions in the lab notebook; for the experimental delivery system, the students answered questions in the "Quiz" section of the D2L Organizational Unit. Figure 5 is an example of how students enter data in the LMS. When the students enter data, the value is checked automatically by the LMS for formatting; the 
correctness of the value recorded must be evaluated by the instructor.

Participants would type their responses into the text box in D2L. To be sure all participants had the same experience, the laptops were issued by the university. These laptops did not have the capability to perform had writing recognition, therefore writing with a stylus was not possible.

Before the experimental laboratory session, students were given a short 17 item multiple choice survey containing items about the content as well as items on their opinion of online learning. The same questions were given to the participants after the session, with an additional four questions that compared paper and pencil laboratory delivery to the computerized delivery. The physics content area covered was in the area of optics. There was a section on magnification, a section on color mixing and lastly a section on the image formed by a convex lens. The normal time allotted to this investigation is two hours; the students finished the activity in the LMS in a little over an hour. To test the student's opinion of the activity, a pretest was given immediately before the class, and a post-test was given immediately after. The pre-posttests had items to measure both opinions questions as well as content questions.

\section{Findings}

The initial comparison was to see if student responses on the paper and pencil activity were significantly different from those submitted on line. To start, a comparison of the number of words used to answer the question: "Describe how the magnification changed as you changed the distance from the paper to the lens. Does the magnification get larger or smaller with distance?" (Note that the question is presented the same way in the professionally published lab manual.) The group that typed their answer into the LMS averaged 16 words per answer with a standard deviation of 9.5 as compared to students who answered the same question on paper in a previous semester wrote an average of 7.5 words with a deviation of 3.4 This would be expected, since students typically prefer to keyboard rather than write with a pencil

The use of a "digital ruler" In the real situation, students are asked to measure the focal length of a lens directly by tracing rays, identifying the location where the rays cross and then measuring the distance from the focal point of the lens (Figure 6). In two different lab sections, this was done perfectly. The write-up page "Written Lab Manuel Instructions - Finding the Focal Length of a Lens" is presented at the end of this paper.

In the simulation, participants were asked to measure the distance from and " $\mathrm{X}$ " indicating the focal point to the lens. All of the subjects correctly measured the distance, $25 \%$ of the participants did not use the correct units in the measurement. In the typical control group, the written lab manual instruction - Finding the focal length of the lens has students measure a distance on paper.

Directions: Check the box that says "Ruler" in the upper right-hand corner of the simulation. The Ruler will appear. Use the ruler to measure the distance from one of the yellow $X^{\prime}$ 's to the lens. The yellow $\mathrm{X}$ is the focal point of the lens'; you are measuring the focal length.

Due to the timing of the lecture and lab, the students had been introduced to this topic earlier. While not the best of situations; this could not be avoided. The average content gain calculated by dividing the difference between each student's pre-test and post-test scores by that student's pre-test score was found to be 0.052 . The Two-Tailed Sig was 0.869 indicating an insignificant difference. $40 \%$ of the student's scores actually dropped after the laboratory session.

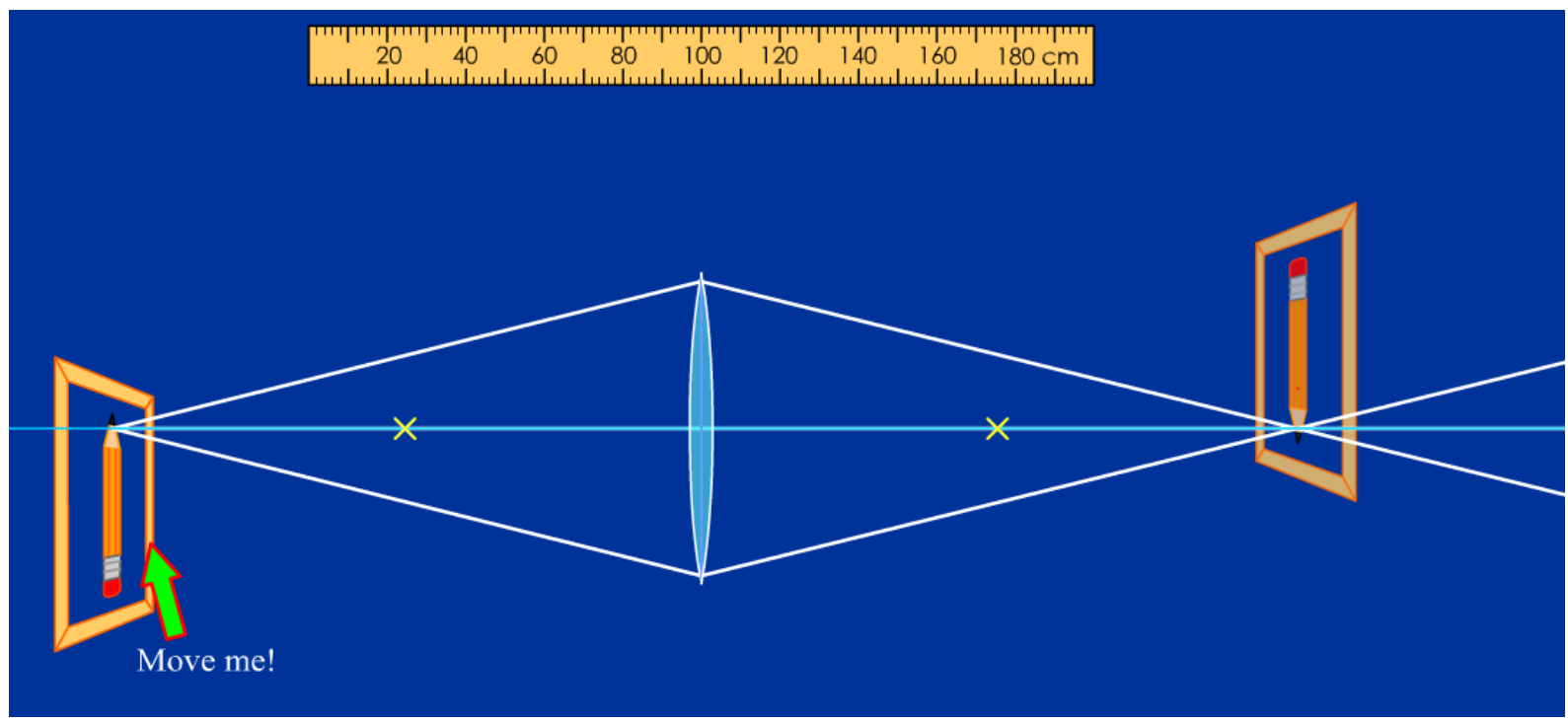

Figure 6. Shot of PhET simulation 
When it comes to the student's opinion of the computerized delivery system, the gain was found to be -0.072 , indicating the students had a small less favorable opinion of the computerized activity after carrying it out than before. The students felt the paper and pencil delivery was easier to use. $28 \%$ felt paper and pencil was much easier and $42 \%$ felt paper and pencil was a little easier. None of the students felt the computer delivered lab was easier than the paper and pencil lab. Since there was no meaningful change in the content score, yet a small change in the opinion of the computerized delivery system, it is conclude that the change in opinion was influenced by the on-line delivery system.

Post item 3. Consider the ease of the delivery method. Specifically, filling in tables on the computer or reading off the screen. When comparing the traditional lab to the computer delivered lab of today:

a) the computer delivered lab was much easier to use.

b) the computer delivered lab was a little easier to use.

c) both delivery methods were equally easy to use.

d) the paper and pencil delivery a little easier to use

e) the paper and pencil delivery much easier to use.

\section{Discussion}

The objective of this project was to fully replace paper and pencil lab manual with an on-line computerized version of a laboratory report. Since Learning Management Systems are so ubiquitous, one of these would be an appropriate platform for developing on-line lab reporting. Full implementation of lab activity as anticipated was not achieved in that the LMS utilized (D2L) could not be modified sufficiently to allow the student user to enter data for use in subsequent calculations. Essentially, there seemed to be no simple mechanism for students to enter data into $\mathrm{D} 2 \mathrm{~L}$, and then have $\mathrm{D} 2 \mathrm{~L}$ process this data to compare student calculations with calculations completed by D2L. This checking process is critical to laboratory exercises.

Secondly, this process was new to the students; therefore the ease of the paper and pencil over computer delivery might be attributed to the novelty of logging on in starting the LMS. The students have used the same LMS in the lecture course, the new venue might have caused a bit of concern.

Use of the LMS in this situation was not for distance education but meant to simplify the instructional process. The use of the LMS had no effect on student learning, and the student felt the computer interface was not as easy to use as paper and pencil. While this does not bode well for this experience for the sake of the student, it would certainly seem to be beneficial to the instructor. The ease of grading; having all of the student responses in electronic form in one place makes grading more efficient. When lab manuals or papers are distributed to the students in the class, edits and changes might need to be done after the fact with ink. An on-line manual will enhance the ability to make these changes. 
Written Lab Manual Instructions - Finding the Focal Length of a Lens from (1)

Rays that approach a lens parallel to the axis meet at a point called the focal point. The distance between the center of the lens and the focal point is called the focal length.

1. The two refracted rays that you traced in part 2 crossed the axis. Mark the axis where these rays crossed. This is the focal point for your lens. Due to imperfections in the lens, these two rays may not meet in exactly one point. In this case, choose the midpoint between the two points as your focal point.

2. Measure the distance between the focal point and the center of your

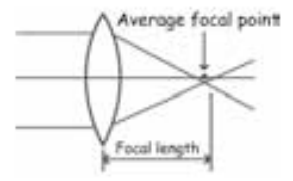
lens. This distance is the focal length of your lens.

3. Label the focal point and focal length on your ray diagram.

Finding an image

When all the rays from a point on an object meet again, they form an image. You can use the laser to locate images formed by your lens.

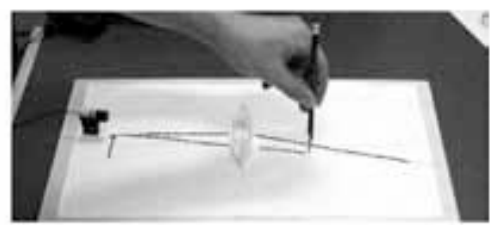

1. Tape two large $(11 \times 17$ inches $)$ sheets of graph paper together so that you have a new $(11 \times 34$ inches) working surface. Draw a horizontal axis all the way across the graph paper.

2. Now draw a vertical line $20 \mathrm{~cm}$ from the left side of the page. Place the lens at the intersection of the lines.

3. Use the laser to center the lens, just as you did in steps 3 and 4 of part 2 . Trace around the lens with your pencil.

4. Draw a vertical arrow $2 \mathrm{~cm}$ from the left edge of the graph paper. The base of the arrow should be on the axis. The tip of the arrow should be $2 \mathrm{~cm}$ above the axis. This anrow will serve as your "object."

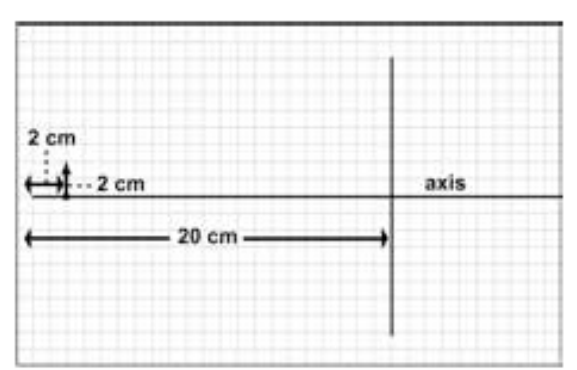

Pre-Lab Survey about on-line instruction Your ID Number (no NAME)

Circle THE LETTER OF option that best represents how you feel about these issues.

DO NOT put your name on the paper. PLEASE REMEMBER YOUR ID NUMBER; THERE WILL BE A POST-SURVEY ON WHICH YOU WILL USE THE SAME NUMBER.

1. To me, having face-to-face contact with my instructor and other students is:

a) Not very important

b) Somewhat important

c) Very important 
2. As a student, I:

a) Can do my assignments, stay focused on the course, and finish coursework ahead of time without being reminded by my instructor.

b) Need help staying focused and usually complete my homework at the last minute.

c) Need a lot of assistance staying focused and motivated to complete my coursework.

3. Estimate your comfort level with using a computer to learn and participate in a course:

a) I use a computer daily for work and other uses and am computer-literate.

b) I have basic computer skills, I am sure I could figure out what I don't know with basic instruction.

c) I'm not sure if my skills are up to date, and computers can frustrate me.

4. Estimate your comfort level with corresponding and discussing coursework online with your instructor and fellow students:

a) I am already comfortable, as I correspond online with colleagues, friends, and family.

b) I don't have much experience online, but I think I could get used to it.

c) I am not comfortable with the idea of discussing topics with students I never meet or see.

5. When an instructor hands out instructions for an assignment, I prefer:

a) Figuring out the instructions myself.

b) Trying to follow the directions on my own, then asking for help as needed.

c) Having the instructions explained to me in detail.

6. When it comes to assessing my own progress, I:

a) Think I can keep tabs on myself, even without frequent feedback from my instructor.

b) Prefer to receive regular feedback from my instructor, but don't mind if I can't.

c) Need to get feedback immediately after turning in a test or assignment. I need to hear from my instructor often.

7. I would consider enrolling in an online course if:

a) I need to complete a degree to advance on the job or get a new job.

b) Taking courses on campus is inconvenient.

c) I have an interest in the topic-I could take the course either on campus or online.

8. Considering my professional and personal schedule, the amount of time I can dedicate to an online course is:

a) 10 hours per week, or more if necessary.

b) 7-9 hours per week, and more if I know it ahead of time.

c) 1-6 hours per week, I don't have much more time than this.

9. My personal and professional schedule is:

a) Predictable: I can generally plan, well in advance, blocks of time to devote to my coursework.

b) Generally predictable: Sometimes last-minute meetings or events come up that I cannot reschedule.

c) Unpredictable: I am seldom sure when I'll have free time that I can set aside for my coursework

The next sets of questions are content questions. This has not been covered in class, but answer as best as you can. The score will not be part of your grade.

10. What is magnification?

a) The ratio of image size to object size

b) The ratio of the object distance to image distance.

c) The size of the image.

d) All of the above are magnification.

e) None of the above indicates magnification.

11. When using a magnifying glass, how does magnification depend upon the distance from the object?

a) The greater the distance between the lens and the object, the larger the image size

b) The greater the distance between the lens and the object, the smaller the image size.

c) The distance from between the lens and the object have no effect on the image size.

d) The image size does not change. 
12. Which of the following are the primary colors of light?
a) Orange, Blue and Green
b) Yellow, Cyan and Magenta
c) Red, Blue and Green
d) Red, Cyan and Yellow
e) None of the above

13. Object and image for a plane mirror lie
a) along the same plane.
b) equal distances from the mirror.
c) at right angles to each other.
d) all of these
e) none of these

14. When light passes through an ordinary window pane, its angle of emergence is
a) usually less than its angle of incidence.
b) always less than its angle of incidence.
c) the same as its angle of incidence.
d) usually more than its angle of incidence.
e) always more than its angle of incidence.

15. A "burning glass" used to concentrate sunlight in a tiny spot is a
a) converging lens.
b) diverging lens.
c) either
d) neither

16. The type of lens that spreads parallel light is a
a) converging lens.
b) diverging lens.
c) combination converging-diverging lens.

17. Which of the following can be projected onto a viewing screen?
a) a real image
b) a virtual image
c) both

\section{REFERENCES}

[1] Gnitetskaya, N. T. g. t. d. r., Ivanova, B. E. 1.-i. m. r., \& Cherednychenko, I. A. (2014). LMS and Power Point Physics Lectures. Applied Mechanics \& Materials (519-520), 1605-1608.

doi:10.4028/www.scientific.net/AMM.519-520.1605

[2] Caminero, A. C., Hernández, R., Ros, S., Tobarra, L., Robles.-Gómez, A., \& Pastor, R. (2013). Comparison of LMSs: Which is the most suitable LMS for my needs? International Journal of Emerging Technologies in Learning, 8, 29-36. doi: 10.3991/ijet.v8iS2.2758

[3] Martín-Blas, T., \& Serrano-Fernández, A. (2009). The role of new technologies in the learning process: Moodle as a teaching tool in Physics. Computers \& Education, 52(1), $35-44$.

doi:http://dx.doi.org/10.1016/j.compedu.2008.06.005

[4] Crippen, K. J., \& Earl, B. L. (2007). The impact of web-based worked examples and self-explanation on performance, problem solving, and self-efficacy. Computers \& Education, 49(3), 809-821. doi: DOI 10.1016/j.compedu.2005.11.018

[5] Lee, Y. J. (2010). Effects of Instructional Preparation Strategies on Problem Solving in a Web-Based Learning Environment. Journal of Educational Computing Research, 42(4), 385-406. doi: Doi 10.2190/Ec.42.4.B

[6] Chandra, V., \& Watters, J. J. (2012). Re-thinking physics teaching with web-based learning. Computers \& Education, 58 (1), 631-640.

doi:http://dx.doi.org/10.1016/j.compedu.2011.09.010

[7] Psycharis, S., Chalatzoglidis, G., \& Kalogiannakis, M. (2013). Moodle as a Learning Environment in Promoting Conceptual Understanding for Secondary School Students. Eurasia Journal of Mathematics, Science \& Technology Education, 9(1), 11-21.

[8] McKagan, S. B., Perkins, K. K., Dubson, M., Malley, C., Reid, S., LeMaster, R., \& Wieman, C. E. (2008). Developing and researching PhET simulations for teaching quantum mechanics. American Journal of Physics, 76(4), 406-417. doi: doi:http://dx.doi.org/10.1119/1.2885199

[9] Jeschofnig, L., \& Jeschofnig, P. (2011). Teaching Lab Science Courses Online: Resources for Best Practices, Tools, and Technology. San Francisco, CA: Jossey-Bass.

[10] Hsu, T. (2002). Foundations of Physical Science Investigations (First ed.). Peabody, Mass: Cambridge Physics Outlet. 